\title{
Bovine Campylobacteriosis and its Economic Importance: A Review
}

\author{
Ahmed seid* \\ Wolaita sodo university, Ethiopia
}

Submission: February 20, 2019; Published: March 29, 2019

*Corresponding author: Ahmed seid, school of veterinary medicine, Wolaita sodo university, Wolaita sodo, Ethiopia

\begin{abstract}
Bovine genital Campylobacteriosis (BGC) is a venereal disease. C. fetus subsp. Venerealis (Cfv) and C. jejuni are the most important species associated with lowered fertility and abortion in cattle. This organism is found worldwide and causes significant economic losses in endemic areas where appropriate management has not been instituted. The prevalence of BGC was higher in older bulls. The organism establishes itself in the prepuce of the male but does not interfere with semen quality or breeding ability. Bovine venereal Campylobacteriosis is transmitted mainly by natural service. Organisms introduced into the cervico-vaginal area at estrus do not establish themselves in the uterus until the progestational phase. Later the bacteria spread to the uterus and oviducts resulting in endometritis and salpingitis. Molecular diagnostic methods have been considered to be the most promising for $C$. fetus sub speciation. The presence of older communal bull is the carrier for the disease in heifers and cows. Therefore, farmers must avoid indiscriminate buying of new animals from the market and if replacement is necessary, restrict to a young and practice quarantine and screening for infectious reproductive diseases during the quarantine.
\end{abstract}

Keywords: Bovine genital Campylobacteriosis; Campylobacter fetus; Venereal disease

Abbreviations: AI: Artificial Insemination; BGC: Bovine Genital Campylobacteriosis; CFF: Campylobacter fetus subspecies fetus; CFV: Campylobacter fetus subspecies venerealis; DFAT: Direct Fluorescent Antibody Test; ELISA: Enzyme-Linked Immunosorbent Assay; OIE: Office International des Epizootics; PCR: Polymerase Chain Reaction; RFLP: Restriction Fragment Length Polymorphism

\section{Introduction}

Bovine genital Campylobacteriosis (BGC), also known as bovine venereal Campylobacteri osis (BVC) is a venereal disease. Most members of this genus are pathogenic inhabitants of the reproductive tract, such as $C$. fetus and $C$. jejuni [1]. The usual agent of this sexually transmitted disease is Campylobacter fetus subsp. Venerealis (Cfv) which has been isolated from the reproductive tract of cattle and internal organs of aborted fetus [2]. Campylobacter fetus subsp. Fetus (Cff), C. fetu subsp. Venerealis (Cfv) and C. jejuni are the most important species associated with lowered fertility and abortion in ruminants [3]. The current Campylobacter genus includes twenty-three confirmed species, of which ten are considered of interest in veterinary microbiology, Bovine venereal Campylobacteriosis is associated with poor reproductive performance, early embryonic death and abortion in cattle. Abortions can occur at any time but are most commonly detected at 4th month to end of gestation [4]. Bovine venereal Campylobacteriosis is transmitted mainly by natural service, but infection may also be spread during artificial insemination (AI) using semen from infected bulls or through contaminated equipment [5].
Bovine genital Campylobacteriosis are often difficult to diagnose by culture due to the slow-growing, fastidious bacterium becoming overgrown by contaminants. The gold standard for detection is culture and biochemical testing for identification [6]. The most common diagnostic methods are culture, direct fluorescent antibody test (DFA T), ELISA, PCR. An ELISA is also available to demonstrate the presence of specific anti bodies in the vaginal mucus. Molecular diagnostic methods have been considered to be the most promising for $C$. fetus sub speciation [7]. Recently, a real time PCR assay has also been reported for detection of C fetus subsp. Venerealis directly in clinical samples. Diagnosis currently relies on the identification of the causal bacterium by culture of preputial washing, vaginal mucus or aborted material [8]. Bovine genital Campylobacteriosis dissemination is also encouraged by newly introduced bulls, cows and heifers from endemic herds and lack of effective control of mass cattle movements across inter-national borders [9]. Bulls are carriers and reservoirs for the disease in the herd where bacteria occupy the glandular crypts of the prepuce [10]. The infection spreads mainly by coitus, causing inflammation in the female genital 
tract, reproductive failure and large economic loss for the producer [10].

Therefore, the objectives of this paper are:

a. To review on bovine genital Campylobacteriosis cause, occurrence, method of spread and treatment and as well as its control and prevention.

b. To highlight the economic importance of the disease (BGC) in any cattle producers.

\section{Overview on Bovine Campylobacteriosis}

\section{Etiology}

Bovine genital Campylobacteriosis is caused mainly by Campylobacter fetus venerealis and Campylobacter jejuni. They are motile, gram-negative, curved or spiral, polar flagellated, microaerophilic bacteria [11]. They can be cultured at $37{ }^{\circ} \mathrm{C}$ for at least 3 days in a micro aerobic atmosphere, although it can also grow at $25^{\circ} \mathrm{C}$ [12]. They are motile having a single polar flagellum at one or both ends of the cells with a characteristics corkscrew motion [13]. The colonies are slightly grey-pink, round, convex, smooth and shiny, with a regular edge and a diameter of 1-3 mm [12] (Figure 1) (Table 1).

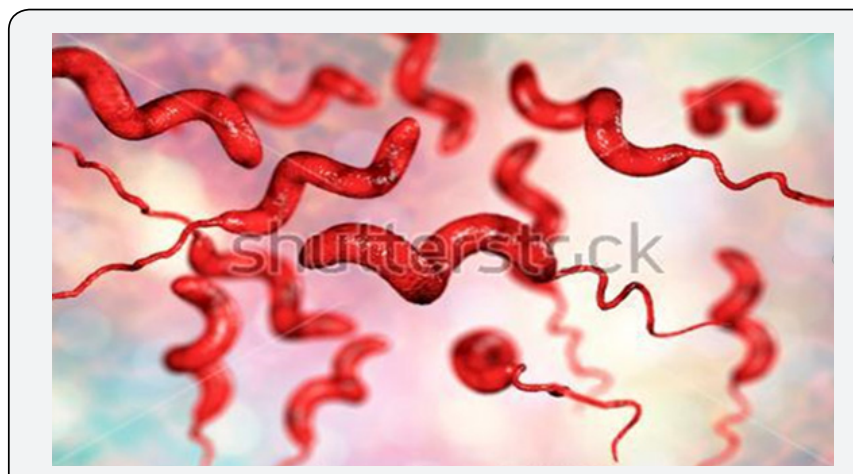

Figure 1: Campylobacter. Fetus.

Table 1: Differential characteristics of Campylobacter species isolated from the bovine genital tract and aborted fetuses [19].

\begin{tabular}{|c|c|c|c|c|c|c|c|}
\hline $\mathbf{2 5}{ }^{\circ} \mathbf{C}$ & $\mathbf{4 2}{ }^{\circ} \mathbf{C}$ & 0xidase & Catalase & NaCL $\mathbf{3 . 5} \%$ & Glycine 1\% & H2S & Nalidixic Acid \\
\hline $\begin{array}{c}\text { C.fetus subsp. } \\
\text { venerealis }\end{array}$ & $\mathrm{V}$ & + & $\mathrm{v}$ & - & - & - \\
\hline C.fetus subsp. fetus & + & + & + & - & + & - & $\mathrm{R}$ \\
\hline C. jejuni & - & + & $\mathrm{V}$ & - & $\mathrm{V}$ & - & $\mathrm{S}$ \\
\hline C.hyointestinalis & - & + & + & - & $\mathrm{V}$ & $\mathrm{V}$ & $\mathrm{R}$ \\
\hline C. sputorum & - & + & $\mathrm{V}$ & + & + & + & $\mathrm{V}$ \\
\hline
\end{tabular}

A. Although C. fetus does not belong to the thermophilic Campylobacter, a considerable number of strains of this species grows at $42^{\circ} \mathrm{C}$.

B. On triple sugar iron agar medium;

C. C.jejuni subsp. Jejune is positive, C. jejune subsp. Doyle is negative.

D. C. jejune subsp. Jejuni is positive, C. jejuni subsp. Doyleis variable.

According to Bergey"s Manual strains are sensitive, however resistant strains have frequently been reported; (+): positive reaction or growth and $(-)$ : negative reaction or absence of growth of the strain on an appropriate medium under specified conditions (see Section B.1.d ii); V: Variable Results; S: Sensitive; R: Resistant.

\section{Epidemiology}

The disease is distributed worldwide despite the absence of reliable data from many countries [14]. The genus Campylobacter contains several bacteria that are pathogenic to domestic and wild animals. The prevalence of BGC was higher in older bulls [13]. The retention of infection in older bulls than the younger bulls may be due to the increase in number and size of the irregular crypts in the epithelium of the penis and persistent colonization of the lower reproductive tract of mature bulls by C. fetus [15]. However, [16] observed that both younger and older bulls could remain carriers after infection. The prepuce of the bulls is the natural reservoir of infection for naive cows through natural mating [14]. New additions of carrier bulls are a particular risk to a disease-free herd whereas the disease is seen mainly in newly introduced cows and heifers in herds where BVC is endemic [17]. Susceptible heifers and cows are infected mainly after being covered by an infected bull but infections could also occur during artificial insemination (AI) with infected semen or through contaminated insemination equipment [18].

Figure 2 shows the global distribution of BVC based on data collected between July to December 2013 [19]. High disease incidences of BVC occur in developing countries, where natural breeding of cattle is widely practiced, compared with low rates of infection in the developed countries, where natural breeding is mainly limited to beef herds. The use of AI in dairy herds has greatly reduced the incidence of BVC. In Africa, BVC may be grossly underestimated because there is no regular monitoring program for this disease, which is indicated by the lack of reporting of disease incidences in most countries [18]. Bovine venereal Campylobacteriosis is transmitted mainly by natural service, but infection may also be spread during artificial 
insemination (AI) using semen from infected bulls or through contaminated equipment. Direct transmission between female cattle is unlikely but bull-to-bull spread of infection can occur during mounting behavior when animals are co-housed [20].

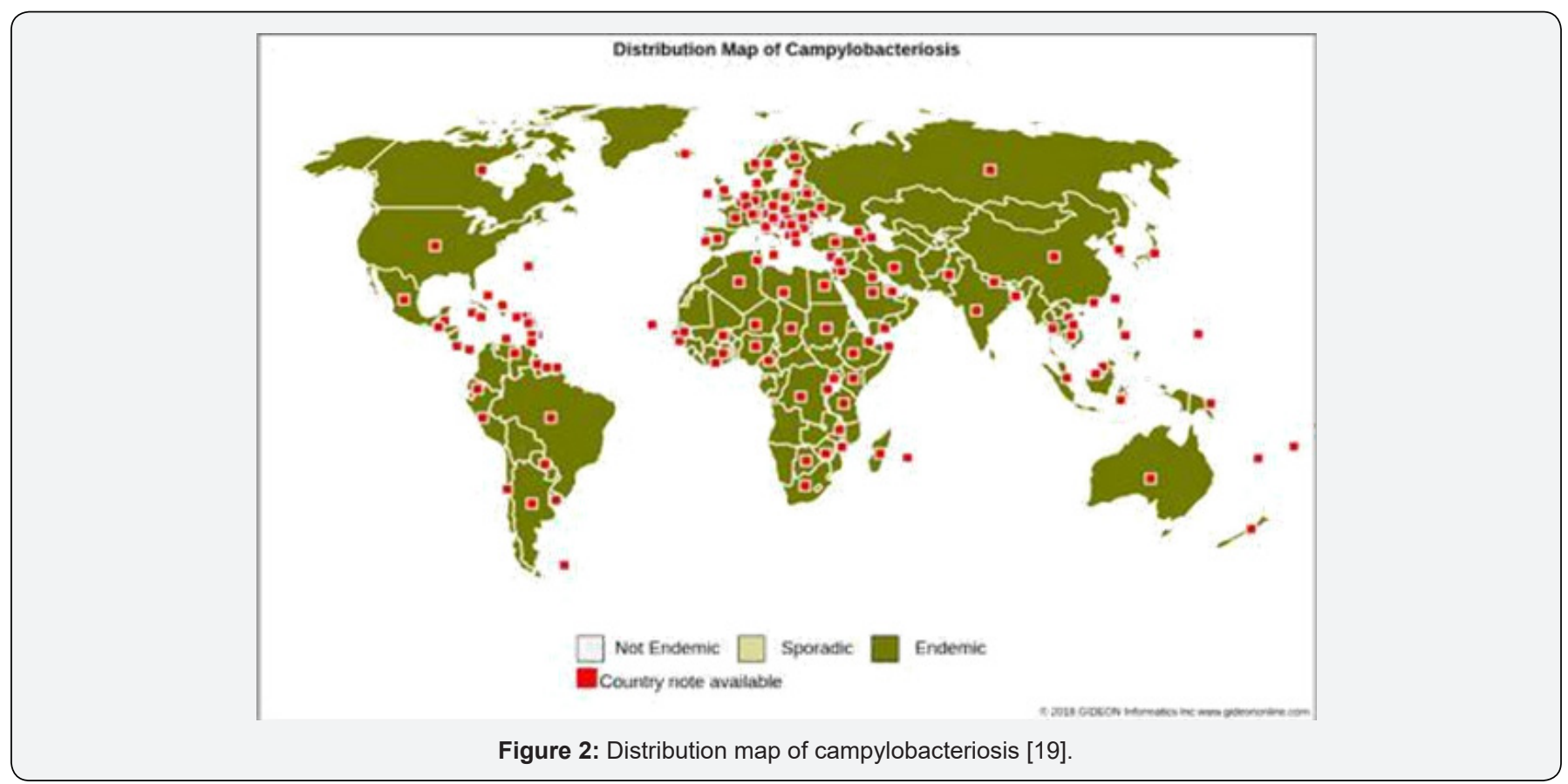

\section{Disease Risks}

In bulls, infection is not accompanied by either pathological lesions or modifications in the characteristics of the semen [21]. The incidence of infection is higher among bulls over five years of age, and this may be attributed to the deeper epithelial crypts in the prepuce and penis of older bulls which allow the pathogen to survive and grow more readily. Persistence of $C$. fetus infection in the bovine genital tract may be due to successive (or intermittent) changes in superficial antigens of the organism. Occurrence of these antigenic shifts in vivo is associated with genomic rearrangement of the sap A gene homologous [22].

\section{Pathogenesis}

The surface of $C$. fetus is protected with S-layer protein antigens called anti-phagocytic macro capsule composed of high-molecular-weight proteins and can change the size and crystalline structure of the predominant protein expressed. This property enhances the virulence of pathogenic C. fetus [23]. The S-layer proteins found in pathogenic Campylobacter have pathogenic significance due to antigenic variation by shifts in expression of the S-layer proteins in chronic venereal infections [24]. The organism establishes itself in the prepuce of the male but does not interfere with semen quality or breeding ability. Organisms introduced into the cervico-vaginal area at estrus do not establish themselves in the uterus until the pregestational phase [25]. Since neutrophils are numerous in the uterus during estrus, it was proposed [26] that they play a major role in preventing colonization at this time. Later in the cycle, when fewer neutrophils are present, $C$. fetus is able to invade the uterus. After colonization in the uterus the organism initiates a local immune response where immunoglobulin"s A, G and M is synthesized [27].

Following invasion of the genital of the naive cows and heifers by $C$. fetus, the organism only establishes itself during the luteal phase of the estrus cycle, localizing in the vagina [14]. The numerous neutrophils in the uterus during estrus help to protect the susceptible host by destroying many of the organisms [26] and infection during the luteal phase does not spread any further and has no effect on fertility in 10 to $20 \%$ of cases. In the remainder, the organisms migrate through the cervix into the uterine body after five to seven days and then may continue to spread during the following weeks. Colonization of the uterus stimulates a local immune response in which $\operatorname{IgG}, \operatorname{IgM}$ and $\operatorname{IgA}$ are produced [27].

The duration of protective immunity acquired after natural infection is two to four years. Bovine genital Campylobacteriosis interferes with placentation causing lowered fertility, early embryo mortality and abortion in females [28]. Female cattle experience transient infertility associated with inflammation of the reproductive tract [13]. Osborne and Smibert reported that the $C$. fetus endotoxins may cause abortion due to hypersensitivity reaction or a drop in the maternal blood progesterone levels. The infection is generally self-limiting, recovery taking three to four months.

In the bull, C. f. venerealisis confined to the fornix of the prepuce and the penis, with a weak and localized antibody response due to insufficient antigenic stimulation as a result of 
antigenic variation and superficial nature of the infection leading to prolonged survival of the organism. The process of infection in the bull is completely different. A bull can be infected when mating with an infective female or when a semen sample is taken using contaminated collection equipment [29]. The prepuce of the bull has crypts in the region where the preputial mucosa joins the penile mucosa (fornix). Here Cfv finds the microaerophlic condition needed for growth and multiplication. The deeper this crypt the better the conditions are for Cfv and as they deepen with aging of the bulls, they more prone to maintain Cfv in its prepuce. In bull there are no symptoms, systemic infection and no transport into the gonad or reproductive gland [29].

\section{Clinical findings}

In bulls, genital Campylobacteriosisis clinically asymptomatic, with inapparent chronic infections, which if not detected allows for the disease to perpetuate within the herd [30]. There are some subtle histological changes, with an increased accumulation of neutrophils deep to the non-keratinized stratified squamous epithelium of the prepuce and glans penis. There is also an infiltrate of lymphocytes and plasma cells penetrating the epithelium and coalescing to form lymphoid nodules within the sub epithelium [31]. In the female, the organisms induce inflammation within the reproductive tract, with a neutrophilic and eosinophilic infiltrate. Like in the male, sub epithelial and periglandular lymphoid nodules develop. Within 7-10 weeks of infection, the increasing inflammatory changes and possibly the trophoblast cause enough damage to kill the conceptus within pregnant females. A small number of cows which abort will also develop a "post coital" pyometra, suspected due to bacterial contamination at the time of fetal loss [31].

CFV in herds, is characterized by temporary infertility, late embryo/early fetal (30-70 days) abortions or sporadic abortions later in pregnancy, as a result of subacute diffuse mucopurulent cervicitis, endometritis and salphingits [32]. Females may present with a late return to estrus, irregular estrus, small calf crops and prolonged calving intervals [33]. Abortions are usually sporadic and generally occur in carriers around the third trimester of pregnancy [32].

\section{Diagnosis}

Dark field or phase contrast microscopy on fresh fetal abomasums content and placental scrapings is a fast and efficient method of diagnosing Campylobacteriosis. The detection of spiral or curved slender rods measuring $0.2-0.9 \mu \mathrm{m} \times 0.5-5.0 \mu \mathrm{m}$ with a rapid and corkscrew-like motility is indicative of Campylobacter spp. This method is also useful for identification of suspect Campylobacter colonies that are suspended in saline prior to examination; however, coccoid forms may occur in culture media. Isolation by culture is the most common BGC diagnostic method and considered to be a gold standard test. Bacterial Campylobacter fetus is a fastidious organism and the accuracy of culture techniques depends on inoculums size, the presence of competing micro flora in the sample, the environmental conditions during collection and transport of the sample to the laboratory, and experienced laboratory technicians [34].

The bacteria need $85 \%$ nitrogen, $10 \%$ carbon dioxide and $5 \%$ oxygen in the atmosphere to survive and replicate. To prevent other bacterial overgrowth while supporting growth of Campylobacter, filtration and/or selective agar must be implemented. There is a range of media described for the isolation of Campylobacter subs, but due to the presence of specific antimicrobials (for example, those containing cephalosporin) some are not suitable for the culture of $C$. fetus. The recommended culture medium for $C$. fetus and $C$. jejuniis Skirrow"s medium. However, Monke extrapolated from differences in C. fetus subsp. venerealis culture yields between 4 and $24 \mathrm{~h}$ and concluded that recovery of $C$. fetus subsp. venerealis is unlikely when transit times are longer than $24 \mathrm{~h}$ [35].

Each subspecies has its own unique pattern of DNA bands on an agarose gel that are displayed after electrophoresis and can be used for distinguishing $\mathrm{Cfv}$ and $\mathrm{Cfv}$. Cfv has a high sequence identity shared with Cff, but there are some unique identifiers [35]. Differentiating characteristics include a pathogenicity island and mobility genes such as insertion sequence transposes, and these have been used in the design of several PCR primer sequences. The most reliable and quantitative being Primer MG3F/MG4R for the carbon starvation protein gene found in both $C$. fetus subspecies and the Primer VenSF/VenSR, a fragment of the parA gene which is exclusive for Cfv [36].

PCR may be combined with other molecular techniques in order to increase its sensitivity, such as restriction fragment length polymorphism (RFLP) or amplification [36]. Due to the recent publication of the complete genome of $\mathrm{CFV}$, improved diagnostics such as real time PCR have been developed allowing for detection of $\mathrm{C}$ fetus venerealis directly from clinical samples, limiting the need to perform prior culturing [37]. The multiplex assay described by is widely used for the identification and differentiation of $C$. fetus subsp fetus and C fetus subsp. Venerealis isolates and has been useful for the direct detection of $C$. fetus subsp fetus in abomasal samples from aborted fetus. This assay, targeting the cst A gene, was adapted in the development of the multiplex assay 16, which can differentiate between cultures of C. fetus and C. jejuni, as well as another Campylobacter spp [38]. An ELISA has been developed to detect antigen-specific secretory IgA antibodies in the vaginal mucus of cattle that are suspected of being previously infected with C fetus subsp. venerealis. With a reported specificity of $98.5 \%$, the IgA ELISA appears to be the current test of choice for the retrospective diagnosis of bovine Campylobacteriosis [33].

\section{Treatment}

Whole herd treatment of Cfv is considered to be impractical due to the lack of overt clinical signs at the initiation of the disease process. There is anecdotal evidence of spontaneous 
recovery from bovine venereal Campylobacteriosis occurring in young bulls. Successful local and systemic antibiotic therapy has been reported in bulls less than 3 years old, while culling of older bulls is usually recommended. Streptomycin is the most extensively used antibiotic, although streptomycin resistant strains of $C$. fetus have been reported [39]. Treatment regimens include infusion into the preputial cavity, systemic therapy or a combination of both. Treatment of infected heifers and cows is not recommended because results are poor and most females develop protective immunity enabling them to resist re-infection (Table 2).

Table 2: Drugs used for treatment of bovine campylobacter [1].

\begin{tabular}{|c|c|c|c|}
\hline Drug & Dosage, Route and Withdrawal Time & Adverse Effect & Drug Resistance \\
\hline Erythromycin & Dose: 4-25mg/kg daily Route: i.m, oral withdrawal = 7-14 days & & No \\
\hline fluoroquinolone & $\begin{array}{c}\text { Dose: } 3-20 \mathrm{mg} / \mathrm{kg} \text { ) Route: i.m., s.c. or orally, every } 6,12 \text { or } 24 \text { h. } \\
\text { Withdrawal time: as species of animal }\end{array}$ & $\begin{array}{l}\text { Neurotoxicity, vomiting, } \\
\text { diarrhea, convulsions }\end{array}$ & No \\
\hline streptomycin & $\begin{array}{c}\text { Dose: } 7.5-12.5 \mathrm{mg} / \mathrm{kg} \text { every } 12 \mathrm{~h} \text { Route: i.m., s.c. Withdrawal time: } \\
\text { regulated by each country }\end{array}$ & Ototoxicity, nephrotoxicity & No \\
\hline tetracycline & $\begin{array}{c}\text { Dose: } 5-20 \mathrm{mg} / \mathrm{kg} \text { every } 12 \text { or } 24 \text { h, Route: i.m., i.v. or orally. Withdrawal } \\
\text { time }=1-22 \text { days. }\end{array}$ & & Yes \\
\hline
\end{tabular}

\section{Prevention}

Bulls can be vaccinated annually against the disease. Vaccinations are also available for cows and make the animal highly resistant to infection. Biosecurity and screening of bulls bought in can help identify the disease. If a bull has to be bought the best policy is the younger the better. If you have to buy in a mature bull, treat it with antibiotics before it is used to mate cows and use it on a small number of cows only so that its fertility can be monitored before it is used for service in the main herd. Aborted tissues, fetal membranes and discharges are all infectious and should be collected and removed properly. Systemic immunization has been believed to prevent or eliminate $\mathrm{Cfv}$ infection by inducing IgG antibodies in genital secretions and serum, shortening infection and reducing reproductive losses.

\section{Control}

Control measures include utilization of artificial insemination with non-contaminated semen, testing and culling of infected animals, and vaccination of all bulls, cows and heifers. Utilization of artificial insemination exclusively for two breeding seasons is suggested in infected herds due to the fact that $\mathrm{Cfv}$ has been isolated from cows for greater than six months after calving. However, total use of artificial insemination is impractical in range cattle. Hence, most producers utilize management, culling problem cattle and use of virgin bulls, and vaccination as their primary means of prevention and control.

\section{Economic Importance}

Campylobacteriosis has been referred to as the "quiet profit taker" [40] since infection in a herd can easily be overlooked. Infection is usually not suspected until low calving rates are noted within a herd, by which time extensive losses would already have occurred [41]. The primary economic losses incurred by the farmer are due to a decrease in calving percentages, delayed calving, culling of infertile animals and abortions [13]. The diseases tend to occur in areas with extensive cattle management and natural breeding [36]. Pregnancy rate in BGC can be as low as $20 \%$ and abortion rate as high as $10 \%$. Sterility may occur in up to $11 \%$ of infected heifers. This infection can prevent the implantation of a fertilized egg, or more commonly results in the loss of the developing embryo in the uterus. When this happens, the animal usually returns to estrus, but often with prolonged and irregular cycles. Campylobacteriosis in cattle can cause sporadic abortions, temporary or permanent sterility, irregular heats due to early embryonic death, and disruption of the breeding regime. This can lead to heavy economic losses as the animals are out of production for months and repeatedly return to service period [1].

Research by Akhtar [42] indicated that infection with Cfv in dairy herds negatively influenced the production of milk in dairy herds but this was not quantified [43]. indicated that in Australia Campylobacteriosis is responsible for significant reproductive wastage in infected beef and dairy herds. It was estimated that during the first year of infection, gross profit margins may be reduced by as much as $66 \%$ representing a large economic loss for producers. When the disease becomes established within a herd, profit margins may be as much as $36 \%$ below those of noninfected herds [44]. Campylobacteriosis is currently classified by the OIE as a "List B" notifiable disease since it is deemed to have socioeconomic and/or public health implications. Consequently, the presence of the disease influences the international trade of animals and animal products. Freedom from infection with $\mathrm{Cfv}$ is a requirement of many countries for the import and export of bovine semen, embryos and cattle, as well as for health certification of bulls in semen production and distribution centers. For this reason, accurate and reliable diagnostic tests for the diagnosis of Campylobacteriosis are essential [45-48].

\section{Conclusion and Recommendations}

In conclusion, Bovine genital Campylobacteriosis is a bacterial disease caused mostly by Campylobacter fetus subsp. fetus (Cff), and Campylobacter fetus subsp. Venerealis (Cfv). They are the most important species associated with lowered fertility, early embryonic death and abortion in cattle. Bovine genital Cam- 
pylobacteriosis is transmitted mainly by coitus and also during artificial insemination (AI) by using semen from infected bulls or through contaminated equipment. The presence of older communal bull is the reservoir for the disease. In heifers and cows the bacteria during copulation spread to the cervix and uterus resulting in endometritis and salpingitis. The disease is asymptomatic and more confined locally to preputial epithelium called crypts in the bull $[49,50]$. The disease is generally self-limiting in females. The first steps in the investigation of a potential bovine venereal Campylobacteriosis problem are to review the herd reproductive history, to conduct a biosecurity and to establish the presence or absence of associated clinical signs.

Base $\mathrm{d}$ on the above conclusion, the following recommendations are forwarded:

a. Farmers should ensure that their initial stocks of cattle are acquired from better managed farms rather than from the open market.

b. There should be compulsory vaccination of calves and adults' cattle against Campylobacteriosis.

c. Farmers should avoid the use of communal bulls for reproduction.

d. Replacement and virgin-breeding bulls must be quarantined and tested.

\section{Acknowledgements}

First of all, I would like to thank God, the almighty, most merciful, self -sufficient master; whom all creature of the world by having full of things; that no one is out of his control and he open the right way for all to believe on him. In addition, I would like to thank all of my families those are supporting me economically and morally in all my educational levels. Last but not least, I would like to thank all my lecturers teaching me in the campus and my entire lovely classmate students, who support me anything I want to do this paper.

\section{References}

1. AU-Ibar (2013) TADs and Zoonoses Compendium: Campylobacter Infections.

2. Truyers I, Luke T, Wilson D, Sargison N (2014) Diagnosis and management of venereal ampylobacteriosis in beef cattle. BMC Veterinary Research 10: 280.

3. Vargas AC, Costa MM, Vainstein MH, Kreutz LC, Neves JP (2003) Phenotypic and molecular characterization of bovine Campylobacter fetus strains isolated in Brazil. Vet Microbiol 93: 121-132.

4. Julie Gard BS (2016) Bovine Genital Campylobacteriosis - A Review. Int J Vet Sci Res 2(1): 029-031.

5. Modolo JR, Lopes CA, Genari T (2000) Occurrence of Campylobacter in the genitals of teaser bulls maintained at an embryo transfer center. Arquivo Brasileiro de Medicina Veterinária e Zootecnia 52(2): 96-97.

6. Koya A (2016) Bovine genital Campylobacteriosis: isolation, identification and virulence profiling of Campylobacter fetus subsp. venerealis in a small animal model.
7. Schulze F, Bagon A, Müller W, Hotzel H (2006) Identification of Campylobacter fetus subspecies by phenotypic differentiation and PCR. Journal of clinical microbiology 44(6): 2019-2024.

8. Iraola G, Hernández M, Calleros L, Paolicchi F, Silveyra S, et al. (2012) Application of a multiplex PCR assay for Campylobacter fetus detection and subspecies differentiation in uncultured samples of aborted bovine fetuses. Journal of veterinary science 13(4): 371-376.

9. Woldehiwet Z, Odiawo GO, Pawadiwa A (1989) Isolation of Campylobacter fetus subsp. Venerealis from bulls in a beef herd in Harare. Zimbabwe Vet J 20: 37-40.

10. Chaban B, Chu S, Hendrick S, Waldner C, Hill J (2012) Evaluation of a Campylobacter fetus subspecies venerealis real time quantitative polymerase chain reaction for direct analysis of bovine preputial samples. Can J of Vet Res 76: 166-173.

11. Kahn M, Line S (2010) Overview of bovine genital Campylobacteriosis. The Mer, C. ck Veterinary Manual, $\left(10^{\text {th }}\right.$ edn), Merck Sharp and Dohme Corp, a subsidiary of Merck \& Co, Whitehouse Station, NJ, USA.

12. OIE (2011) Bovine Genital Campylobacteriosis. In: Manual of Diagnostic Tests and Vaccines for Terrestrial Animals. Paris, France: World Organization for Animal Health pp. 661-670.

13. Irons PC, Schutte AP, Van Der Walt ML, Bishop GC (2004) In: Infectious Diseases of Livestock.2. Coetzer JAW, Tustin RC, editor. Cape Town: Oxford University Press. Genital Campylobacteriosis in cattle pp. 14591468.

14. Mshelia GD (2008) Bovine Venereal Campylobacteriosis and Reproductive Efficiency in the Lake Chad Basin of Nigeria. PhD Thesis, University of Maiduguri, Nigeria.

15. Cobo ER, Corbeil LB, Bon Durant RH (2011) Immunity to infections in the lower genital tract of bulls. J Repro Immunol 89: 55-61.

16. Swai ES, Hulsebosch J, Vander Heijden W (2005) Prevalence of genital Campylobacteri osis and trichomonosis in crossbred breeding bulls kept on zero-grazed smallholder dairy farms in the Tanga region of Tanzania. J S Afr Vet Assoc 76: 224-227.

17. Mshelia GD, Amin JD, Woldehiwet Z, Murray RD, Egwu GO (2010) Epidemiology of bovine venereal Campylobacteriosis: geographic distribution and recent advances in molecular diagnostic techniques. Reproduction in domestic animals 45: 5 .

18. OIE (2007) Bovine genital Campylobacteriosis, Office international des epizootics, disease timelines, Czech Republic. In: WAHID Interface.

19. Berger S (2018) Infectious Diseases of the World. Gideon Informatics Inc, USA.

20. Hoffer MA (1981) Bovine Campylobacteriosis. Can Vet J 2: 327-330.

21. Cho HJ, Masri SA, Deregt TD, Yeo SG, Thomas EJG (1991) Sensitivity and specificity of an enzyme-linked immunosorbent assay for the detection of bovine viral diarrhea virus antibody in cattle. Can J vet Res 55: 56-59.

22. Eaglesome MD, Garcia MM (1997) Disease risks to animal health from artificial insemination with bovine semen. Revue scientifiqueet technique-Office international des epizooties 16: 215-225.

23. Casademont I, Chevrier D, Guesdon J (1998) Cloning of a sapB homologue (sapB2) encoding a putative $112 \mathrm{kDaCampylobacter} \mathrm{fetus}$ S-layer protein and its use for identification and molecular genotyping. FEMS Immunol Med Microbiol 21: 269-281.

24. Thompson SA (2002) Campylobacter surface-layers (S-layers) and immune evasion. Ann Periodontol 7: 43-53.

25. Schurig GD, Hall CE, Burda K, Corbeil LB, Duncan JR (1974) Winter infection patterns in heifers following cervicovaginal or intrauterin e instillation of Campylobacter (Vibrio) fetus veneralis. Cornell vet 64: 533-548. 
26. Corbeil LB, Corbeil RR, Winter RJ (1975) Bovine venereal vibriosis: activity of inflammatory cells in protective immunity. Am J Vet Res 36: 403-406.

27. Van Aert A, De Keyser P, Florent AF, Bouters H, Vandeplassche M, et al. (1977) Nature of Campylobacter fetus agglutinins in vaginal mucus from experimentally infected heifers. Brit Vet J 133: 88-94.

28. Campero CM, Anderson ML, Walker RL, Blanchard PC, BarBano L, et al. (2005) Immunohistochemical identification of Campylobacter fetus in natural cases of, bovine and ovine abortions. J Vet Med 52: 138-141.

29. Sansone NB (2005) Diagnosis of bovine venereal Campylobacteriosis in New Zealand: a thesis presented in partial fulfilment of the requirements for the Master of Applied Science at Massey University. Palmerston North, New Zealand.

30. Ondrak JD (2016) Tritrichomonasfoetus prevention and control in cattle. Veterinary Clinics: Food Animal Practice 32(2): 411-423.

31. Hum S, Hornitzky M, Berg T (2009) Bovine genital Campylobacteriosis. Australia and New Zealand Standard Diagnostic Procedures, Department of Agriculture, Fisheries and Forestry.

32. Givens MD (2006) A clinical, evidence-based approach to infectious causes of infertility in beef cattle. Theriogenology 66(3): 648-654.

33. Hum S, Brunner J, McInnes A, Mendoza G, Stephens J (1994) Evaluation of cultural methods and selective media for the isolation of Campylobacter fetus subspvenerealis from cattle. Australian veterinary Journal 71(6): 184-186.

34. Monke HJ, Love BC, Wittum TE, Monke DR, Byrum BA (2002) Effect of transport enrichment medium, transport time, and growth medium on the detection of Campylobacter fetus subsp. venerealis. J Vet Diagn Invest 14: 35-39.

35. Michi AN, Favetto PH, Kastelic J, Cobo ER (2016) A review of sexually transmitted bovine trichomoniasis and Campylobacteriosis affecting cattle reproductive health. Theriogenology vol. 85(5): 781-791.

36. Bondurant RH (2005) Venereal diseases of cattle: Natural history, diagnosis, and the role of vaccines in their control. Vet Clin North Am Food AnimP ract 21: 383-408.

37. Hum S, Hornitzky M, Berg T (2009) Bovine genital Campylobacteriosis. Australia and New Zealand Standard Diagnostic Procedures, Department of Agriculture, Fisheries and Forestry.

38. Hum S, Quinn K, Brunner J, On SL (1997) Evaluation of a PCR assay for identification and differentiation of Campylobacter fetus subspecies Australian Veterinary Journal, 75(11): 827-831.
39. Hänel I, Hotzel H, Müller W, Tomaso H (2011) Antimicrobial susceptibility testing of German Campylobacter fetus subsp. venerealis isolates by agar disk diffusion method. 124(5-6): 198-202.

40. Thompson SA, Blaser MJ (2000) Pathogenesis of Campylobacter fetus infect ins in Campylobacter. Nachamkin I, Blaser MJ (Eds.), Washington, USA, American Society of Microbiology pp. 321-347.

41. Van Bergen MA, Linnane S, van Putten JP, Wagenaar JA (2005) Global detection and identification of Campylobacter fetus subsp. venerealis. Rev Sci Tech 24: 1017-1026.

42. Akhtar S, Riemann HP, Thurmond MC, Franti CE (1993) The association between antibody titers against Campylobacter fetus and reproductive efficiency in dairy cattle. Veterinary Research Communications 17(3): 183-191.

43. Hum S (2004) Vibriosis of cattle. Agfact A2, 9(7): 1-2.

44. Mc Millen L, Fordyce G, Doogan VJ, Lew AE (2006) Comparison of culture and a novel 5 Taq nuclease assay for direct detection of Campylobacter fetus subsp. venerealis in clinical specimens from cattle. J of Clin Microbiology, 44(3): 938-945.

45. Oyarzabal OA, Wesley IV, Harmon KM, Schroeder-Tucker L, Barbaree JM, et al. (1997) Specific identification of Campylobacter fetus by PCR targeting variable regions of the $16 \mathrm{~S}$ rDNA. Veterinary microbiology 58(1): 61-71.

46. Anderson ML, Blanchard PC, Barr BC, Hoffman RL (1990) A survey of causes of bovine abortion occurring in the San Joaquin Valley, California. J Vet Diagn Invest 2(4): 283-287.

47. Berlinerund Munchenertierarztliche Wochenschrift, Hjerpe CA (1990) Bovine reproductive disease vaccines. Vet Clin N Am Food Anim.

48. Eaglesomea M, Garcia M (1992) Microbial agents associated with bovine genital tract infections and semen. Part I. Brucellaabortus, Leptospira, Campylobacter fetus and Tritrichomonasfoetus. Vet Bull 62: pp.743-775.

49. Mukasa-Mugerwa E (1989) A review of reproductive performance of female Bosindicus (Zebu) Cattle. ILCA Monograph No.6.Offices International des Epizooties. Terrestrial Animal Health Code.

50. Skirrow S, Bon Durant R (1998) Bovine trichomoniasis. Vet Bull 58: 591-603.

Your next submission with Juniper Publishers
will reach you the below assets
- Quality Editorial service
- Swift Peer Review
- Reprints availability
- E-prints Service
- Manuscript Podcast for convenient understanding
- Global attainment for your research
- Manuscript accessibility in different formats
( Pdf, E-pub, Full Text, Audio)
- Unceasing customer service
Track the below URL for one-step submission
https://juniperpublishers.com/online-submission.php

